\title{
Envisioning Yoga Therapy as A Stride towards Successful Ageing
}

K K Boban*, A Shahin Sultana† and Susheela Gopinath ${ }^{\ddagger}$

\section{Abstract}

Geriatric Social Work is becoming ostensibly crucial in contemporary times. The modes and modalities being discussed in strengthening geriatric well-being deserve mammoth attention. In this context, Yoga Therapy is being envisioned as one among the strides towards Successful Ageing. The practice of Yoga in India can be traced to thousands of years back and has rolled down to generations through innumerable strategies. Yoga is considered as a practical philosophy that facilitates people to improve their Quality of Life. It is a discipline that has evolved in response to the problems in contemporary society without losing its true essence. Research in the field of Yoga Therapy advocates it to be the best means to ensure the quality living, especially in old age. Yoga helps to mitigate, alleviate, and reverse many of the geriatric problems, both physical and mental. The proposed paper is based on an experimental study conducted among elderly people in Kerala. The paper describes Yoga in its essence based on Patanjaly Yoga Sutra thereby scientifically analyzing its effect on our body. It emphasizes the practicality for quality living in old age and provides suggestions for successful ageing.

Keywords: Successful Ageing, Yoga therapy, Patanjaly yoga sutra, Quality of life

"PhD Scholar, Dept. of Social Work, Pondicherry University, India; kkbobsun@gmail.com

tReader, Dept. of Social Work, Pondicherry University, India

¥Yoga Acharya, Ashtanga Yoga Centre, Kochi, India 


\section{Background}

In ancient times, wise Indian sages suggested several paths to ultimate self-realization. These were BhaktiYoga, Karma Yoga, Jnanayoga and Rajayoga ${ }^{1}$. Among these, Rajayoga was systematized by sage Patanjali ${ }^{2}$ (200 BC) into what later came to be known as Ashtanga Yoga ${ }^{3}$, which is the most popular system of Yoga today. Later, Swami Kuvalayananda ${ }^{4}$ pioneeredYoga Therapy in 1921 by applying modern medical science to study the physiological effects on therapeutic application of Yoga. Gradually its practices spread out of India. Now, Yoga Therapy has become a very popular alternative therapeutic tool in many of the life style diseases, worldwide. Yoga Therapy comprises a wide range of mental and physical practices ranging from postural and breathing exercises to deep relaxation and Meditation. It promotes total health of body in case of specific ailments. Regular practice of Yoga not only helps in physical fitness but also, in preventing the occurrence of many such ailments which invariably result from hectic pace of modern life style. Yogic practices are effective in treatment of various functional and psycho- physiological disorders of Cardio-Vascular, Musculoskeletal, Gastro- Intestinal, Respiratory and Nervous systems. The effect of Yoga therapy is widely used in Gynecology \& Obstetrics, Gastro-Entrology, and Geriatrics also (Gauchard et al., 1999).

\section{Successful Ageing \& Yoga Therapy}

According to World Health Organization (WHO, 2004), "Health is a state of complete physical, mental, social and spiritual well-being, and not merely the absence of disease or infirmity." The application of this definition in old age leads to the concept of Successful Ageing. Successful Ageing refers to modification of behavioral process to achieve the best possible outcome to ageing.

The concept of Successful Ageing has three main components:

a. Low probability of diseases and disease-related disability

b. High cognitive and physical functional capacity

c. Active engagement with life ( Rowe \& Kahn, 1997)

Later in 2002, Crowther et al. suggested a fourth component of spirituality to Successful Ageing, which is directed to positive 26 
actions that promote the life enhancing beliefs, and thereby positive Health, which was confirmed by $\mathrm{WHO}$ in its definition of Health.

Old age is a time of susceptibility to more ailments such as Arthritis, Rheumatism, Incontinence, and High Blood Pressure. This raises the need for the geriatric to stay fit and healthy during this stage. The degeneration of the body sets some limits to the type of exercises they can do. Milder forms of exercises such as jogging, brisk walking, and even Yoga are seen as suitable for persons in this age category. Apart from its physiological benefits, Yoga Therapy is proved beneficial for psycho-spiritual enhancement of mind. Regular yoga practices create mental clarity, increase body awareness, relieve chronic stress patterns, relax the mind, center attention and sharpen concentration. It increases self-awareness, improves cognitive performances, brings positive mood, better social outlook, and spiritual well-being. In this way, by modifying our life in association with yoga exercises, pranayama ${ }^{5}$, meditation and balanced diet, anyone can achieve Successful Ageing, as it is to start from younger ages itself as a routine.

\section{Rheumatoid Arthritis and Yoga Therapy}

Arthritis is one among the common diseases in the world. It affects $40 \%$ of Indians aged $45-64$ and $60 \%$ of those aged 65 and older (Yung, 2002). As seen here, vulnerability of people to Arthritis increases as we grow older. Arthritis is actually a term used to refer to a group of more than 100 diseases with a common factor: inflammation of joints. The common types of Arthritis are osteoarthritis, rheumatoid arthritis, gout and fibromyalgia. Arthritis results from deterioration of soft tissues that cover and protect joints. When this happens, the bones rub against each other, which is so painful (Minor, 1999). While doctors are still on the process of determining what exactly causes Arthritis, many believe that the deterioration may be caused by pressure of gravity on the jointsthe tear and wear of life, so to speak. Also, obesity and heredity contribute to deterioration. The stresses of daily life and anxiety are also causes to Arthritis. Any way, it can be seen that there is a close correlation between poor muscle health, disproportionate body weight and unhealthy life style (Madanmohan \& Balakumar, 1994). 
Women are found more prone to rheumatoid arthritis and osteoarthritis. $80 \%$ or rheumatoid arthritis cases in India are in women. For Gout, nearly all those suffering from it are men (90\%) (Yung, 2002).

Arthritis falls in the third group of 'Tridoshas'6 which is due to the imbalance in homeostasis of body functions, the root cause of rheumatoid arthritis. With yoga, mostly the body aspects and the life can be greatly enhanced. Yoga poses can help strengthen the joints, which is crucial in preventing and dealing with arthritis. It makes the joints function normal, thus reducing the risk of stiffness. With its virtue of balance, yoga practices help to regulate the levels of uric acid in the body. Obesity may also be avoided through the practice (Schell et al., 1994).

For rheumatoid arthritis yoga therapy suggests a combination of the following:

- Loosening exercises and yogic postures like Bhujangasana, Dhanurasana, Shalabhasana, Ardha-Matsyendrasana, Ardha-Chandrasana and Vakrasanawhich which energize the 'Prana'7

- 'Shadkriyas's to drain the shedding inner wastes of body

- Pranayama and Meditation

- Satvic life which includes a balanced satvic diet and herbal medicines

More importantly Yoga can lead to an overall healthier life style that can enhance our resistance not only to arthritis but to other sickness as well.

\section{Rheumatoid Arthritis as a hindrance to Successful Ageing}

Rheumatoid arthritis is one of the major orthopedic complaints among old age, especially among aged women. By deteriorating the strength of tissues, it gives way to unbearable pain and thereafter immobility (Schell et al., 1994). Thus, it is a threat to Successful Ageing of one. Due to the ineffectiveness of prolonged medicine and increased burden of medical expenses, people suffering from such kind of diseases hesitate to continue their treatment by suppressing the pain and ailments silently. This may further lead to more complications. Yoga and pranayama are found 28 
very much effective in prevention of arthritic complaints and maintenance of well-being of many physical ailments. Thus, Yoga therapy becomes the easiest and cheapest alternative therapeutic approach. It can be practiced in non-clinical atmosphere also. As per population projections, the population of elderly is in a hike; accordingly their associated problems will also be. To meet such a situation, surely we need alternatives. The purpose of this study is to suggest Yoga Therapy as an effective, alternative therapeutic tool for arthritic elderly as a stride towards their Successful Ageing.

\section{Material and Methods}

The study aimed at examining the effectiveness of Yoga in rehabilitation of elderly who are suffering from rheumatoid arthritis, and thereby in successful ageing. It focused on the overall development of patients, specifically in their activities of daily living, Psycho-social well-being and Quality of life which are the major contributing factors in successful ageing among elderly.

\section{Research Design}

The study followed a quasi-experimental design along with participant observation, which was further supported by five case studies in order to ensure reliability. The study was conducted among 15 purposefully selected clients ( 6 male +9 female), who were reported to have chronic problems of rheumatoid arthritis at Ashtanga Yoga Centre, Cochin of Kerala State in India.

In a controlled non-clinical environment, the so called 15 arthritic elderly persons were observed continuously for two months with daily 2-hours sessions of aasana, pranayama and meditation. As proposed by Yoga therapy, a satvic balanced diet also was suggested to the clients under observation. Various physical (Activities of Daily Living - 3 point ADL scale) and psycho-social (Psycho-Social Development - 2 point scale) aspects of their daily life were measured using standard scales, 'before' and 'after' the experimental intervention. The study compared the development in their Quality of Life also, by using a 5 point QOL Scale by WHO. For the statistical analysis, paired t-test was used with SPSS. 


\section{Hypotheses}

1. Yoga Therapy has a significant effect in improvement of daily physical activities of arthritic elderly.

2. Yoga Therapy has a significant effect in development of psycho-social conditions of elderly.

3. Yoga Therapy has a significant role in promoting the quality of life of arthritic elderly

\section{Results}

The paired t-test results for the hypotheses are shown in Tables1, 2 \& 3. Table 1 shows the improvement in Activities of Daily Living, which is a direct measure of Physical Development. In PsychoSocial aspects as per Table 2, four dimensions are tested separately, viz, self-esteem, autonomy, emotional stability and social competency, which collectively contribute to Psychological Development. Finally, the development in overall Quality of Life of the clients is shown in Table 3.

Table1: Paired t-Test for Development in ADL

\begin{tabular}{|c|c|c|c|c|c|}
\hline ADL & $\mathrm{N}$ & Mean & Std. Deviation & $\mathrm{t}$ & Sig. \\
\hline Before & 15 & 8.34 & 5.615 & \multirow{2}{*}{6.277} & $\mathrm{p}<.05$ \\
\hline After & 15 & 5.20 & 5.016 & & \\
\hline
\end{tabular}

Basic Activities of Daily Living (ADL) include bathing, eating, dressing, using the toilet, transferring from one place to another, and walking. One of the more striking characteristics of the aging process is impaired motor performance (Wiswell, Tuggle \& Turner, 1990), which is demonstrated in the slowing of movements, the loss of fine coordination and a decrease in maximum strength. Training for real-life function means helping clients regain or improve their ability to stand up, sit down and maintain general independence. These activities require coordination, synchronization and a certain amount of strength. Analysis of functional ability does not require a lot of statistical normative data. Older adult clients are the least concerned about how they compare to the norm. Instead, they are very concerned with their own 30 
progress, which can record and report (Gregory, 2013). Table1 shows the result of Paired t-Test on the improvement in Activities of a Daily Living, before and after the therapeutic intervention of Yoga. The reduced mean difference indicates, the scale is reverse reading and there is a significant improvement in ADL at 5\% level of significance. Hence it can be concluded that Yoga therapy has a significant effect in physical development of arthritic elderly.

Table 2: Paired t-Test for Psycho-Social Development

\begin{tabular}{|c|c|c|c|c|c|}
\hline Self Esteem & $\mathrm{N}$ & Mean & Std. Deviation & $t$ & Sig. \\
\hline Before & 15 & 1.71 & 2.037 & \multirow{2}{*}{-7.400} & \multirow{2}{*}{$\mathrm{p}<.05$} \\
\hline After & 15 & 96.14 & 11.423 & & \\
\hline \multicolumn{6}{|l|}{ Autonomy } \\
\hline Before & 15 & 3.8 & 2.495 & \multirow[t]{2}{*}{-7.123} & \multirow[t]{2}{*}{$\mathrm{p}<.05$} \\
\hline After & 15 & 8.17 & 1.963 & & \\
\hline \multicolumn{6}{|c|}{ Emotional Stability } \\
\hline Before & 15 & 1.54 & 2.034 & \multirow[t]{2}{*}{-6.961} & \multirow{2}{*}{$\mathrm{p}<.05$} \\
\hline After & 15 & 7.06 & 3.429 & & \\
\hline \multicolumn{6}{|c|}{ Social Competence } \\
\hline Before & 15 & 2.4 & 1.988 & \multirow[t]{2}{*}{-6.795} & \multirow[t]{2}{*}{$p<.05$} \\
\hline After & 15 & 6.97 & 2.885 & & \\
\hline
\end{tabular}

Table 2 collectively analyses the paired $\mathrm{t}$ - test result for psychosocial development of the clients before and after the intervention. According to Cope (2013), a psychotherapist and author of Yoga and the Quest for the True Self, hatha yoga's postures improve mood by moving energy through places in the body where feelings of grief or anger are stored. "Hatha yoga is an accessible form of learning self-soothing," he says. "These blocked feelings can be released very quickly, [creating a] regular, systemic experience of well-being." Here the three psychological factors show the various components of our psychological well-being which along with social competence contribute to the improvement in total psycho-social wellbeing which is a direct measure of successful ageing. All the results show significant variation, which is progressive in nature at $5 \%$ level. Diagrammatic representation of the development is shown in Figure-1. 


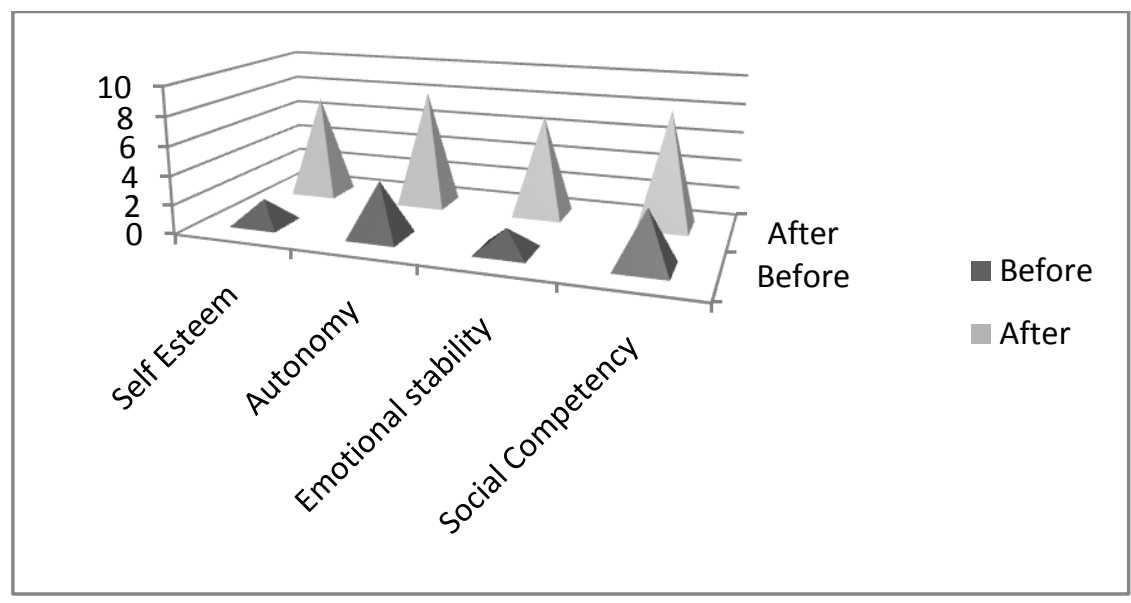

Fig 1: Development in Psycho-Social Aspects: Figure shows the change in Psycho-social aspects after intervention

Table 3: Development in Quality of Life (QoL)

\begin{tabular}{|l|l|l|l|l|l|}
\hline Quality of Life & $\mathrm{N}$ & Mean & Std. Deviation & $\mathrm{t}$ & Sig. \\
\hline Before & 15 & 77.91 & 5.767 & -7.518 & $\mathrm{p}<.05$ \\
\cline { 1 - 5 } After & 15 & 96.14 & 11.423 & & \\
\hline
\end{tabular}

Health surveys indicate that adults with arthritis report significantly greater Quality of Life impairment compared to adults without arthritis. Specifically, those who have arthritis reported fair to poor health approximately three times more often than did those without arthritis (Fontaine, 2012). From the yogic perspective, the issue of quality of life has to be seen from both material and spiritual angles. Yet, the material angle of quality of life can be simplified by considering it as an expression of the spiritual perspective. Indeed, the spiritual side of quality of life takes credit for the material side that becomes just a matter of a right attitude towards material things. In own turn, the spiritual side of quality of life has to be seen from body and mind perspectives. The body issue is essential, as the harmonization of the body is a solid foundation for addressing the issues of the mind that becomes a tool of extension, the organ and function through which we experience the world (Sarbatoare, 2013). 
Table 4 shows the result of paired t-test on improvement of QoL before and after the intervention. The result implies that there is a significant improvement of QoL which can be confirmed as the result of harmonization of body and mind perspectives, from the baseline. Figure-2 indicates the graphical representation of the same.

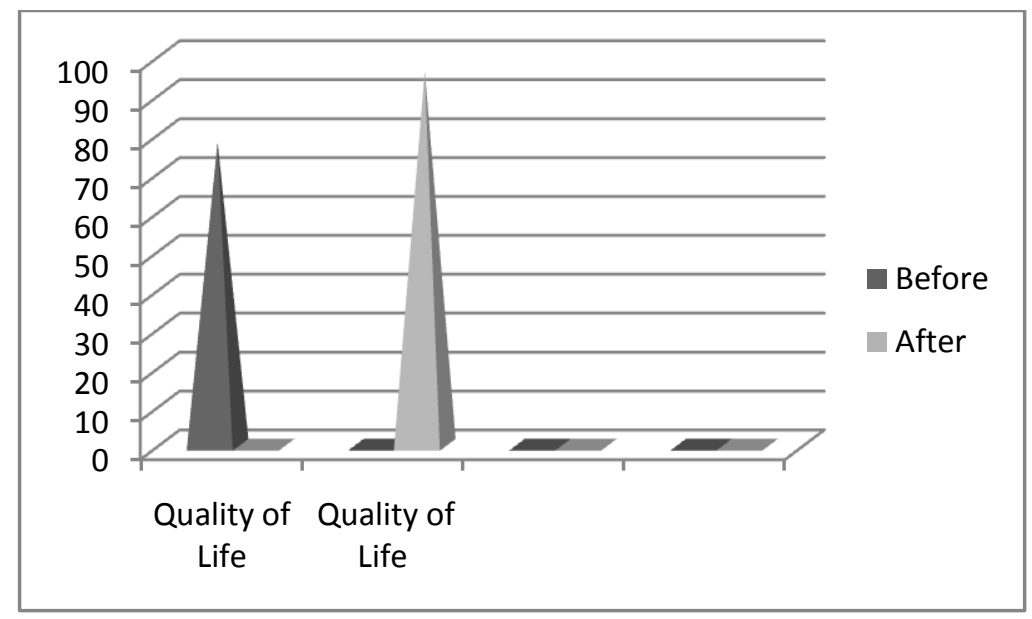

Fig 2: Development in Quality of Life: The figure illustrates the change in QoL after the intervention

\section{Findings and Discussions}

\section{Demographic}

As an integral science, Yoga is acting beyond caste, creed, race, sex, and age. Still the satvic practice of Yoga follows some mantras, and Hindu rituals. This religious stigma over yoga is somewhat deterrent to people of other religions to adopt it in their daily routine, at least in Indian situations. Yoga Therapy can be designed by avoiding these religious practices. Accordingly, the practitioners also have to change their attitude. Women also hesitate to undergo yoga therapy, or even any other exercises. Hence they are prone to obesity and in turn more viable to locomotive problems, due to arthritis-like ailments.

At the same time men showed more improvement in their "joint" functions. But age is a factor that prevents them from undergoing 
rigorous exercises, even certain asanas also. In these cases, Yoga therapy advises certain milder poses and loosening exercises along with pranayama and meditation so that it prevents the body muscles and tissues from stiffening. (Madanmohan \& Balakumar, 1994). Of course, education and marital status are always supporting factors in the effectiveness of Yoga Therapy. A thorough understanding of the way in which it works, will contribute positively. Also, the family support and care act accordingly to acquire better improvement in any ailments especially in old age.

\section{Therapeutic}

Rheumatoid arthritis is a mobility problem caused by slowly disintegrating joints. Even Yoga cannot bring any magical effect on this, all on a sudden. But on continuous practice, surely the improvement can be observed (Forest et. al, 1994). This is why the improvement in daily activities showed less association. All the respondents uniquely opined that they felt certain kind of total flexibility and relaxation during the intervention. Follow-ups found most of them discontinued their practices, especially the women. But on continuation of the practice, the body can sustain its flexibility, mental stability and spiritual calmness. Unless one is dedicated, one has to suffer the pain as a part of life. The session was done in group that it was beneficial to the clients in the level of a group therapy. Group sessions helped them among themselves, through their mutual support and motivational approaches. Peer pressure and peer adaptation are the contributing factors in group activities.

Similarly, Yoga is always better to practice under a therapist or trainer (Nair, 1995). "Yoga students may benefit from their relationship with the yoga instructor, Stephen Cope said, which can provide a "container" or a safe place for investigating, expressing and resolving emotional issues. The instructor's encouraging and accepting words may also help students defeat self-limiting notions." If the client-therapist relationship is based on mutual respect and belief, it is helpful to the respondents for free selfexpression and ventilation of their problems. This in turn becomes 34 
individual case work. Better the therapist being a good counselor so as to guide them in a positive way.

\section{Rehabilitative}

The rehabilitation management of individuals with rheumatoid arthritis is imperative to decrease the potential long-term disabilities as noted above. Specifically, individuals with rheumatoid arthritis are at risk of decreased flexibility, muscle atrophy, decreased muscle strength and reduced cardiovascular endurance. Deficit in such areas will lead to functional compromise and increased health care expenditures. Therefore, a multifactorial approach utilizing medications and rehabilitative techniques is necessary. Fortunately, under proper counseling, individuals with rheumatoid arthritis can safely exercise, improving overall physical fitness, greater ease for activities of daily living and an improved sense of well being. Rehabilitative techniques include appropriate periods of rest and activity modification; therapeutic modalities such as heat/cold or electrical stimulation; bracing and adaptive equipment (Krabak et al. 2013). Through statistical analysis of hypotheses, it is established that there is a significant role of Yoga Therapy in rehabilitation of elderly especially who are suffering from rheumatoid arthritis. Thus as an integrated science, Yoga Therapy fulfills its aim by integrating physical, social, psychological and emotional well-being, thereby leading to successful ageing.

\section{Conclusion}

Ageing is an inevitable process that all humans have to undergo. Because of this ageing process, the different parts and muscles of the body degrade in their performances as well. Yoga provide better enhancement in its performances or curing various ailments that come as a result of these natural processes of the body. In summary, yoga can be a meaningful and enjoyable alternative to traditional forms of exercise such as aerobics or aquatic exercise with important health benefits. Yoga can play an important role in reducing stress and frustration that results from pain and disability, and increasing positive feelings and well-being (Haaz, 
2012) Thus by considering the importance of Yoga Therapy, for successful ageing, it is advised to start from an early age as a living culture and it is to be implemented through day care centres, old age homes, elderly clubs, schoolsetc. It is happy to know, some of the schools of international level nowadays, adopt Yoga as a part of their curriculum. The modern medicine suggests multidisciplinary team approach in treatment. Yoga Therapist also must be a part of this team. Even though yoga originated in India, the attitude of a good percentage of people towards yoga is as a religious business or as a part of high society life. More awareness on the importance of Yoga and more number of training centers are to be established so that Yoga could be accessible for all common people for their better health outcomes and thereby a successful later life.

\section{Endnotes}

1. Basic vedic tenets of self-realization of ancient Indian literature.

2. Master of Yoga (200BC) who systemized the Raja yoga system as Ashtanga Yoga

3. The most popular Yoga system having 8 limbs or steps, which are yama, niyama, Asana, Pranayama, Pratyahara, Dharana, Dhyana, Samadhi

4. Indian Pioneer of the scientific study of Hathayoga(1883-1966)

5. Breathing control exercises, which is ultimately about Controlling the life-force (prana)

6. One of the basic principles of Ayurveda, dealing with the imbalance of biological humours of the organism which causes illness. Three components are Vata (air), pitha (fire), Kapha(water) in the human body.

7. Basic life-force

8. Hathayogic process of cleansing internal body wastes through Dhouti, Basti, Neti, Nauli, Trataka, \&Kapalabhati

\section{References}

Andrew, M. K., Mitnitski, A.B., Rockwood, K. (2008) Social Vulnerability, Frailty \& Mortality in Elderly People, PLOS One, 3(5) Retrieved from http://www.plosone.org/article/info\%3Adoi\%2F10.1371\%2Fjournal. pone. 0002232 
Brian, M. D. \& Evan M. D. O. (2012). Rehabilitation Management for Rheumatoid Arthritis, The John Hopkins Arthritis Centre. Retrieved on February 05, 2013 from http://www.hopkinsarthritis.org/patientcorner/disease-management/rehabilitation-managementrheumatoid-arthritis-patients/

Chow R. K. (2005) Life's Quest for spiritual well-being: A holistic and gerontological nurse perspective, Imprint 52(4) 80-3

Crowther M. R, Parker M.W, Achenbaum W.A, Larimore, W. L, Koenig H.G .(2002) Rowe and Kahn's model of successful aging revisited: positive spirituality - the forgotten factor. Gerontologist 42, 613-620.

Forrest, G. \& Rynes, R. I. (1994). Exercise for Rheumatoid Arthritis, Contemporary Internal Medicine, 6(11) 23-8

Gass, R. C. (1999). Discovering Spirit in Sound, New York NY: Broadway Books.

Gauchard, G. C. Jeandel, C. Tessier, A. Perrin, P. P (2008) Beneficial effects of proprioceptive physical activities on balance control in elderly human subjects, Neuroscience Letters. Retrieved on February 05, 2013 from http://www.mendeley.com/catalog/beneficial-effect-proprioceptivephysical-activities-balance-control-elderly-human-subjects/

Govindhannair, Yogacharya, (1995).Yoga Paadaavali, , Kottayam: DC Books

Gregory L. W. (2013). Training goals for Older Adults, Health Net, Retrieved on February 05, 2013 from http://www.healthy.net/ scr/ article.aspx?Id=289

Judith P, Kristine, A, \& Sarah, H. (2010). Key concepts in Social Gerontology, NewDelhi: Sage Publications

Kevin, F. (2012). Artritis and Health-related Quality of Life, The John Hopkins Arthritis centre. Retrieved from http://www.hopkinsarthritis.org/patient-corner/diseasemanagement/quality-of-life-and-arthritis/

Madanmohan, T. D. P, \& Balakumar, B. (1994). Effect of yoga training on reaction time, respiratory endurance, and muscle strength, Indian Journal of Physiology and Pharmacology. Retrieved on February 05, 2013 from

http://www.worldacademicunion.com/journal/SSCI/SSCIvol05no0 3paper06.pdf

Margi, C. (2009). Yoga for anxiety and depression, Harvard Health Publications, Retrieved on February 05, 2013 from www.health.harvard.edu/newsletters/Harvard_Mental_Health_Lette r/2009/April/Yoga-for-anxiety-and-depression 
Minor, M. A. (1999) in K. DBrandt \& W.B. Saunders (Eds) Exercise in the treatment of Osteo-Arthritis, Rheumatic disease clinics of North America., Philadelphia. 25(2):397-415

Newsome, G. (2002). Guidelines for the management of rheumatoid arthritis: update. Journal of American Academy Nurse Practitioners 2002; 14(10) pp 432-437.

Octavian, S. (2010). Yoga Breathing, Retrieved on February 05, 2013 from http://www.healthandyoga.com/html/news/octavian_long.aspx

Rita K. C. (2005). Life's Quest for Spiritual Well-Being- A holistic and Gerontological Nurse's Perspective, Geriatric Nursing.

Rowe, J. W., Kahn, R. L. (1997). "Successful Aging". The Gerontologist 37 (4): 433-40. doi:10.1093/geront/37.4.433

Schell, F .J., Allolio, B., Schonecke, O. W. (1994). Physiological and Psychological effects of Hathayoga exercises in Healthy Women, International Journal of Psychosomatics. 41(1-4):46-52.

Steffany, H. (2012). Yoga for Arthritis, The John Hopkins Arthritis Centre. Retrieved on February 05, 2013 from http://www.hopkinsarthritis.org/patient-corner/diseasemanagement/yoga-for-arthritis/\#studies

Swadi, S. Y. (2009). Trends of Adjustment among elderly, Participative Development 8(2), Centre for Social Research \& Development, Pune , India.

Wiswell, T. E., Tuggle, J. M., \& Turner, B. S. (1990). Meconium aspiration syndrome: have we made a difference? Pediatrics 85:715-721

Yung, R. (2002) Primer on Geriatric Care- A clinical Approach to the older patient, in Rosenblat, D. E. \& Natarajan, V. S. (Eds), Musculoskeletal Diseases in Elderly, Kochi: Amrita Institute of Medical Sciences. 